\title{
TEACHING ENGLISH GRAMMAR USING PROBLEM BASED LEARNING JO. WITH PUZZLE AT ENGLISH EDUCATION STUDENT OF IKIP SILIWANGI BANDUNG
}

\author{
Acep Haryudin ${ }^{1}$, Trisnendri Syahrizal ${ }^{2}$ \\ ${ }^{1}$ IKIP Siliwangi \\ ${ }^{2}$ IKIP Siliwangi \\ ${ }^{1}$ haryacep@gmail.com, ${ }^{2}$ trisnendri@gmail.com
}

\begin{abstract}
The the purposes of this research was to find out students dificulty in mastering Grammar, and to find out the suitable method in improving students' grammar mastery. The method of this research was Action Research as the application of fact finding to practical problem solving in social situation by involving the collaboration and cooperation of researcher and practitioners. The research took place at IKIP Siliwangi, focused on class A2 academic year 2016. Subjects of the research was 45 students of English Education Study Program. The finding and disscussion of this research was that Problem Based Learning (PBL) jo with Puzzle media could improve students' grammar mastery and PBL can be apllied well in teaching grammar for English Education Students of IKIP Siliwangi.
\end{abstract}

Keywords: English Grammar, PBL, Puzzle, Clasroom Action Research

\section{INTRODUCTION}

Teaching is a habitual action specially for teachers or lecturers in some areas of education. Teaching also become the main pital or the key for successful students learning in region of school. Now day, creative, innovative and communicative teaching is expected and become something valuable to improve student in mastering materials for every subject. To be smart teacher or Lecturer is no eazy, they have to find the best strategies, methods and approaches to convey the materials. Many approaches and methods have been tried by English teachers and instructors on teaching English as a foreign language. They do such efforts in order to improve their students mastering English. As we know, English has four basic skills; they are listening, reading, speaking, and writing. To master all of the four basic skills, students must learn the other skills such as vocabulary and grammar as the additional skill. Either vocabulary or Grammar is the two important thing that should be achieved by student in learning English. This assumption arises because vocabularies are very significant on one's mastery of such a language. Stated by Strump and Douglas (2004: 14) also say "We study grammar so that we may speak and write in a clearer and more effective manner". Grammar covers many themes that may confuse students on memorizing and understanding them. However, since grammar is important to their development of English mastery, they have to study it well.

Many difficulties are faced by English teachers during the process of teaching grammar since grammar need to be not only memorized but also understood by the students. It relies more on the concepts. Once the students comprehend the concept, they will easily develop their ability in solving problem relate with grammar. To deliver the concept, teachers must 
put their effort to seek for a suitable learning method for the students. In this opportunity the researcher tried to implement the Problem Based Learning as one solution in solving the grammar mastery difficulties for english education study program of IKIP Siliwangi. Finally this research title was Teaching English Grammar Using Problem Based Learning Jo. with Puzzle at English Education Student of IKIP Siliwangi.

The research questions of this research was, how was the difficulty faced by students in mastering Grammar? How to improve students' ability in mastering grammar mastery?. The objectives of this resaerch was, to find out students' dificulty in mastering Grammar, and to find out the suitable method in improving student grammar mastery.

\section{A. Literature Review}

\section{Grammar Mastery}

a. Definition of Grammar Mastery

There are several definition from the expert such as According to Galaso (2002: 3 ) and Radford (2009:1) that Grammar is divided into two inter-related studies consisting morphology and syntax. Morphology is the study of how the word is formed out of smaller units. And syntax, on the other hand, is the study of how word are formed in a phrase, a clause or a sentence. Here we can understand that study grammar is not only focus on one unit (grammar it self), but study grammar means students study both morphology and syntax although these two areas of study have own areas to be specific. And grammar is the principals to combine or change the rules of language such as tenses to form a meaningful and correct language.

b. The Aspect of Grammar Mastery

Donald and Kneal (2001: 71) draw the traditional grammar assign words to different classes, known as part of speech. on the other hand, according to Brindley (1994:201:202) state that some aspect of grammar are:

1) Knowledge of some terminology, example noun, verb, but not confined to part of speech

2) The ability to write well-constructed and effective prose, using the grammar of standard English were appropriate

3) Knowledge of sentence structure

4) Knowledge of word formation

c. Students Problem Learning Grammar

Learning is a process for student gaining the science or knowledge in several learning experiences. It is understandable that English students at university also get some difficulties in mastering Grammar. This problem happened because they have no enough English knowledge when they was at Senior or Junior High School. Learning Grammar means learning rule of English and according to Widdowson (1990: 86), “.... grammar is not a constraining imposition but a liberating force: it frees us from a dependency on context and a purely lexical categorization of reality". Some factors that students get difficulties learning grammar based on real field, are:

1) Students do not understand between function and form of words (verb, noun, adjective etc.)

2) Students have difficulties in comprehending Grammar Formula

3) Students have no critical thinking/curiosity

4) There was a gap between high-motivated and low-motivated students

5) Students rarely interacted with the teacher and/or among them 
6) Do not want to be involved in learning process

7) Students have low motivation in learning English

d. Some Solutions

To cope with the problems mentioned above, teachers may refer to the cooperative language learning (or simply cooperative learning) approach. This is an approach to teaching that makes maximum use of cooperative activities involving pairs and small groups of learners in the classroom. Olsen and Kagan (1992: 8) define cooperative learning as follows:

Cooperative learning is group learning activity organized so that learning is dependent on the socially structured exchange of information between learners in groups and in which each learner is held accountable for his or her own learning and is motivated to increase the learning of others (cited in Richards and Rodgers, 2001: 192).

Cooperative learning is a systematic and structural teaching strategy. As mentioned in Olsen and Kagan's definition, in cooperative learning, class members are split in small groups. Slavin (1995) states that variety of teaching methods, in which students work in small groups, help them learning academic content. Students need to learn to think, solve problems, and integrate and apply knowledge and skills. In cooperative learning situations, there is a positive interdependence among students' goal attainments: students perceive that they can reach their learning goals if and only if the other students in the learning group also reach their goals.

\section{Problem Based Learning}

Problem-Based Learning (PBL) is an instructional method of hands-on, active learning centered on the investigation and resolution of messy, real-world problems. PBL also is a teaching method in which complex real-world problems are used as the vehicle to promote student learning of concepts and principles as opposed to direct presentation of facts and concepts. In addition to course content, PBL can promote the development of critical thinking skills, problem-solving abilities, and communication skills. It can also provide opportunities for working in groups, finding and evaluating research materials, and lifelong learning (Duch et al, 2001).

PBL can be incorporated into any learning situation. In the strictest definition of PBL, the approach is used over the entire semester as the primary method of teaching. However, broader definitions and uses range from including PBL in lab and design classes, to using it simply to start a single discussion. PBL can also be used to create assessment items. The main thread connecting these various uses is the real-world problem.

Any subject area can be adapted to PBL with a little creativity. While the core problems will vary among disciplines, there are some characteristics of good PBL problems that transcend fields (Duch, Groh, and Allen, 2001):

a. The problem must motivate students to seek out a deeper understanding of concepts.

b. The problem should require students to make reasoned decisions and to defend them.

c. The problem should incorporate the content objectives in such a way as to connect it to previous courses/knowledge. 
d. If used for a group project, the problem needs a level of complexity to ensure that the students must work together to solve it.

e. If used for a multistage project, the initial steps of the problem should be openended and engaging to draw students into the problem.

The problems can come from a variety of sources: newspapers, magazines, journals, books, textbooks, and television/ movies. Some are in such form that they can be used with little editing; however, others need to be rewritten to be of use. The following guidelines from The Power of Problem-Based Learning (Duch et al, 2001) are written for creating PBL problems for a class centered around the method; however, the general ideas can be applied in simpler uses of PBL:

a. Choose a central idea, concept, or principle that is always taught in a given course, and then think of a typical end-of-chapter problem, assignment, or homework that is usually assigned to students to help them learn that concept. List the learning objectives that students should meet when they work through the problem.

b. Think of a real-world context for the concept under consideration. Develop a storytelling aspect to an end-of-chapter problem, or research an actual case that can be adapted, adding some motivation for students to solve the problem. More complex problems will challenge students to go beyond simple plug-and-chug to solve it. Look at magazines, newspapers, and articles for ideas on the story line. Some PBL practitioners talk to professionals in the field, searching for ideas of realistic applications of the concept being taught.

c. The problem needs to be introduced in stages so that students will be able to identify learning issues that will lead them to research the targeted concepts. The following are some questions that may help guide this process:

1. What will the first page (or stage) look like? What open-ended questions can be asked? What learning issues will be identified?

2. How will the problem be structured?

3. How long will the problem be? How many class periods will it take to complete?

4. Will students be given information in subsequent pages (or stages) as they work through the problem?

5. What resources will the students need?

6. What end product will the students produce at the completion of the problem?

d. Write a teacher's guide detailing the instructional plans on using the problem in the course. If the course is a medium- to large-size class, a combination of minilectures, whole-class discussions, and small group work with regular reporting may be necessary. The teacher's guide can indicate plans or options for cycling through the pages of the problem interspersing the various modes of learning.

e. The final step is to identify key resources for students. Students need to learn to identify and utilize learning resources on their own, but it can be helpful if the instructor indicates a few good sources to get them started. Many students will want to limit their research to the Internet, so it will be important to guide them toward the library as well. 
The method for distributing a PBL problem falls under three closely related teaching techniques: case studies, role-plays, and simulations. Case studies are presented to students in written form. Role-plays have students improvise scenes based on character descriptions given. Today, simulations often involve computer-based programs. Regardless of which technique is used, the heart of the method remains the same: the real-world problem.Problem-Based Learning (PBL) is a pedagogical approach and curriculum design methodology often used in higher education and K-12 settings[1][2].

The following are some of the defining characteristics of PBL:

1. Learning is driven by challenging, open-ended problems with no one "right" answer

2. Problems/cases are context specific

3. Students work as self-directed, active investigators and problem-solvers in small collaborative groups (typically of about five students)

4. A key problem is identified and a solution is agreed upon and implemented

5. Teachers adopt the role as facilitators of learning, guiding the learning process and promoting an environment of inquiry

6. Rather than having a teacher provide facts and then testing students ability to recall these facts via memorization, PBL attempts to get students to apply knowledge to new situations. Students are faced with contextualized, illstructured problems and are asked to investigate and discover meaningful solutions.

\section{Proponents believe that PBL:}

1. develops critical thinking and creative skills

2. improves problem-solving skills

3. increases motivation

4. helps students learn to transfer knowledge to new situations

\section{Puzzle/Media}

\section{Teaching Grammar Using Puzzle}

Teaching Using puzzle is one of techniques to increase students interest in learning. Moreover, it is stated in wright that puzzle specifically contribute to:

1) interested and motivation,

2) a sense of the context of the language,

3) a specific reference of stimulus.

\section{The advantages of using puzzle.}

1) Puzzle supplies source of word which can be reconciled by teacher if she/he needs certain illustrations.

2) Puzzle can be inspiration sources for teachers who do not have certain ideas.

3) Puzzle can be used by all teachers. whi need them; the purpose of puzzle can be used by other teacher with different goals.

\section{METHOD}


This research was action research. Burns (1999) defines action research as the application of fact finding to practical problem solving in social situation by involving the collaboration and cooperation of researcher, practitioners, and laymen. Based on this definition, it can be concluded that a lecturer may be a researcher who collaboratively conducts an action research to change what is going on in his classroom, including the approaches, methods, techniques, materials, curriculum, media, evaluation system, classroom management, and classroom setting use in the teaching learning process.

This research tried to find and implement actual actions to improve the quality of grammar learning process for the first year students of IKIP Siliwangi. The lecturer as researcher to find obstacles and weaknesses of grammar learning process, identify the existing problems, and carry out the actions, and then make evaluation, reflection, and discussion of the actions implemented.

\section{Research Setting and Subject}

The research took place at IKIP SIliwangi, focused on class A2 academic year 2016. Subjects of the research was 45 students of English Education Study Program.

\section{Procedure of the Research}

This used the structural steps of action research suggested by Kemmis and McTaggart in Burns (1999:32). They explain that action research occurs through a dynamic and complementary process, which consists of four essential "moments": planning, action, observation and reflection (PAOR)

\section{Planning}

In this step, researcher prepared the lesson plans, the materials, and the research instruments. Lesson plans were used as scenarios of the teaching and learning process. The materials planned were in the form of copied handout. While the instruments such as the interviewed guideline, grammer tests, and the questionnaire were designed by considering the kinds of data needed. The plans for each cycle are described as follows:

\section{a. Cycle I}

\section{1) Planning}

In planning the first cycle, researcher considered the materials which would be taught by reviewing the Basic Competency. Researcher planned to have three meetings in this cycle. Problem Based Learning technique would be applied in each meeting. In addition, researcher decided tenses (simple past) used by considering the Basic Competence, and puzzle as media used in this cycle.

\section{2) Action and Observation}

In this stage, the lesson plans were implemented in the class, the teaching and learning process were observed and recorded in the form of field notes, and some changes were made in relation to the students' learning process. Researcher noted some problems appearing during the teaching and learning process.

\section{3) Reflection}


In this stage, Researcher discussed the problems and solutions in each meeting with other researcher or lecturer, and by the end of the cycle, we discussed the whole stages of the cycle as a consideration to plan for the next cycle.

\section{b. Cycle II}

\section{1) Planning}

In the planning session of this cycle, researcher reviewed the result of the discussion and planned the teaching techniques to solve the problems appearing on the first cycle. The grammar mastery of this cycle was "simple past tense".

\section{2) Action and Observation}

In this stage, researcher implemented the revised method decided in the planning session, and observed its progress. The mistakes, weaknesses, changes and improvements were recorded as a consideration to depict the conclusion about the whole teaching and learning process.

\section{3) Reflection}

In this stage, the implementation and observation of the cycle II were reflected in the discussion between the researcher and other lecturer of Grammar. Moreover, the entire problems, solutions, changes and improvements made in cycle I. Cycle II were discussed to draw the conclusions about the overall teaching and learning process.

\section{Action and Observation}

These research actions were carried out in two cycles. Each cycle was done in three meetings. In the action stage, the lesson plans, the materials and other teaching media were used in the classroom. In this stage, the other English lecturer acted as the observer (abbreviated ET), while I acted as the action taker (R), and the students acted as the subject of learning (Ss).

In this research report, these abbreviations would be used in the tables, field notes and interview transcripts. In this stage, the plans were carried out in the classroom. Besides, the researcher also made some changes and revisions in the use of PBL technique as the solution of the problems. The implementation of the teaching and learning process was observed by the other English lecturer to give feedback on my teaching technique.

\section{Reflection}

In this stage, the resaercher and other English lecturer put heads together to find the best way on how to improve the effectiveness of the teaching learning process so that the improvement expected by the English teacher and I can be achieved. The reflection session was expected to be useful in revising the plan and actions so that the efforts could be done in a better way. While the evaluations were done in three ways, the first was done in every meeting, the second one was done in every cycle, and the last one was done in the end of cycle II to evaluate the whole implemented actions. The evaluations involved me as the researcher and the English teacher.

\section{F. Instruments and Data Collection Technique}




\section{Observation}

Observation can be a very useful research tool. Cohen (2007: 396) says that the distinctive feature of observation as a research tool is that it offers an investigator the opportunity to gather ,live ee data from naturally occurring social situations. In this research, I applied structured and unstructured observations as suggested by Kutner (2007: 28).

A structured observation is very systematic and enables the researcher to generate numerical data from the observations. Cohen (2007: 400) explains that there are five principal ways of entering data onto a structured observation schedule: event sampling, instantaneous sampling, interval recording, rating scales and duration recording. In this study, I applied a rating scale in each meeting in which the English teacher as the observer was required to make some judgements about the students ${ }^{\text {ee }}$ behavior during the action implemented. It consisted of six aspects: (1) Studentse enthusiasm towards the lesson, (2) Students ${ }^{\text {ee }}$ activeness in asking question, giving comment, and responding, (3) Students ${ }^{\text {ee }}$ interest towards learning method, (4) Students' attitude in reading, (5) Students"e activeness in group work, and (6) Students ${ }^{c e}$ attitude in carrying out the test individually. After that, the observer had to enter responses into a rating scale.

On the other hand, I also applied unstructured observation, in which the observer views the overall classroom and assesses a wide variety of teaching behaviors, provides general information about instructional practice and student responses, and are informative when used in conjunction with teacher interviews (Kutner, 2007: 28). In this case, field notes were used as one of the unstructured observation techniques to gather the information about the teaching and learning process in general.

\section{Interview}

The interview is a flexible tool for data collection, enabling multi-sensory channels to be used: verbal and non-verbal. Interviews enable participants - either the interviewers or interviewees - to discuss their interpretations of the world in which they live, and to express how they regard situations from their own point of view (Cohen, et al., 2007: 349).

In this research, interviews were used to gather data about the students ${ }^{\text {ee }}$ feelings during the teaching and learning process, their reflections on learning, their observations during the lessons, their success and difficulties in learning, and their perceptions on the instructional materials.

\section{Questionnaire}

The questionnaire is widely used and useful instrument for collecting survey information, providing structured, often numerical data, being able to be administered without the presence of the researcher, and often being comparatively straightforward to analyze (Wilson and McLean 1994 in Cohen, et al., 2007:317). In this research, close-ended questionnaires were used before the action implementation to gather the data about the students ${ }^{\text {ee }}$ need in English lesson. The open-ended questionnaires were also applied in this research after the action implementation to gather the data about the students ${ }^{\text {ee }}$ perceptions on the use of jigsaw technique and the improvements they made after using reading jigsaw technique. 


\section{Pre- and Post-Tests}

Henning, et al. (2009:128) say that pre- and post-tests offer two benefits: they provide a useful approach for diagnosing strengths and weaknesses of classes, individuals, or subgroups; pre- and post- test are also more useful for identifying problems with learning than suggesting new teaching strategies. The pre-test results can identify strengths and weaknesses of students. In this research, the pre-test was applied before the action implementation while the post-tests were applied by the end of each cycle. Henning asserts that post-tests data can provide helpful insights into student learning process and the effectiveness of teaching strategies.

\section{RESULTS AND DISCUSSION}

\section{Results}

This research is done as one of the creative effort in developing the quality of learning is by using and developing model and learning media become more creative and innovative. First, when teaching the learning model used and developed is a model of Problem Based Learning (PBL) learning with the use of media in the form of Puzzle. In this description researchers use PBL as a model of learning and Puzzle as a medium that is used when teaching because in the learning process students often find a variety of problems that must be solved, in addition, according to the researcher of this model of learning is more desirable and make students more motivated to improve learning. After finding the right learning model to be used in the teaching process, the researcher sought to re-locate a suitable medium and certainly creative to use together. Researchers use Puzzle as an appropriate and fun medium when used with PBL while doing the learning process. However, each PBL or Puzzle is familiar and often used before, but in this case the researcher develops the model and the learning medium becomes more creative and more fun.

Researchers want to explain about the use of media Puzzle for the learning process more creative and alive. The media puzzle used is something different. Puzzles here are wordshaped in a paper that has been prepared before the learning activity begins. Students must rearrange the sentences correctly based on the order of sentences that I show to the students before they are reassembled in the form of Puzzle, students are given 5 minutes to remember the correct order of sentences without being recorded in a book or piece of paper, this activity is done in groups 5 groups) that have been formed before, the number of sentences that are presented about 10 sentences, the value of each sentence is 10 points.

The researcher prepares a paper containing the sequence number 1-10 according to the number of sentences present in the puzzle and the prepared paper also contains only the points in the position of the words corresponding to the number of words in the sentence contained in the Puzzle. After the exhaustion time, each student is asked to come to the front of the class in turns and each advanced student may only fill one word at the points on the paper provided before the second and third points are filled by the second student and third and so on until the empty points are filled by the words they fill in turns.

Each group has a paper that must be filled in turn by each member of his group. Each group is given a duration of 15 minutes to compose a word puzzle, after the second runs out, the representatives of each group are asked to come to the front of the class and are 
asked to explain the team's division of tasks, the difficulty in working on, and the concepts they understand in a sentence. This model is used in one of the subjects namely English Grammar. Value to be built is to hone students learn to build cooperation among members in a group, increase the creativity of how to divide tasks in a group, and hone students to think critically. Each time after completion of teaching, In this study was conducted to evaluate both the style of teaching, students and the model and learning media that has been used in the process of learning in the classroom.

Secondly, it starts from observation of one of the obstacles that causes the decreasing of the students' capability to the material presented during the learning process which is less focus in following the learning process because there are still many students who play the gadget / hp although it has been warned before the lecture starts to not play / use HP / gadgets during the learning process takes place. To address this problem, the researchers look for ideas so that students can focus on learning activities. Therefore, it is necessary to find creative models to create a learning technique that can solve the above problems, especially if learning requires discussion, so that in the process can improve the quality of learning.

\section{CONCLUSION}

Based on the data finding and discussion, finally researcher can conclude that teaching grammar using Problem Based Learning with pzzle as media can give positif effect to the students. Student can master the material well and can enjoy the learning process. The change can be shown in every cycle from the teaching process.

\section{ACKNOWLEDGMENTS}

The writers would like to thank to Allah SWT for giving me the opportunity to work on this journal.

\section{REFERENCES}

Barrows, H. S. (1986). A taxonomy of problem?based learning methods.Medical education, 20(6), 481-486.

Savery, J. R., \& Duffy, T. M. (1995). Problem based learning: An instructional model and its constructivist framework. Educational technology, 35(5), 31-38.

Boud, D., \& Feletti, G. (1997). The challenge of problem-based learning. Psychology Press.

Barrows, H. S. (1996). Problem?based learning in medicine and beyond: A brief overview. New directions for teaching and learning, 1996(68), 3-12.

Burns, Anne. 1999. Collaborative Action Research for English Language Teacher. Cambridge: Cambridge University Press.

Cohen, L., Manion, L. and Marisson, K. 2007. Research Method in Education. 6th Ed. New York: Routdlege.

Henning, John E.; Stone, Jody M.; and James L..2009. Using Action Research to Improve Instruction: an Interactive Guide for Teachers. New York and London: Taylor \& Fancis Routledge.

Richards, J.C. and Rodgers, T.S. 2001. Approaches and Methods in Language Teaching. 2nd Ed. New York: Cambridge University Press.

Slavin, Robert.E. 1995. Cooperative Learning: Theory, Research, and Practice. 2nd Ed. Massachusetts: Allyn \& Bacon. 